\title{
Knowledge and awareness of diabetes amongst diabetes patients in Wardha region
}

\author{
Shivkant Kide • Ashish Rangari • Rajshree Shiral • Nita Mane • \\ Priyanka Yadav • Komal Ambulkar • Chandrashekhar Tenpe • \\ Angad Patole • Meher Tundulwar • Sumit Rathod
}

Received: 28 March 2013 / Accepted: 5 December 2013 /Published online: 30 January 2014

(C) Research Society for Study of Diabetes in India 2014

\section{Dear Editor,}

As a lifelong disease, type 2 diabetes increases morbidity and mortality and decreases the quality of life $[1,2]$. India has among the highest number of diabetic patients and awareness and knowledge of diabetes is poor [3, 4]. Wardha region is located on the north-eastern side of the Maharashtra (India). The total diabetes patients were included in this study was 1,580 aged $>30$ years $(N=1,580$, urban $=894$, rural $=686)$. Details regarding diabetes were collected using STEP-1(knowledge and sign and symptoms), STEP-2 (awareness) questionnaire. Data was collected of personal demographic characteristics, lifestyle, behavior, history of diabetes and hypertension, face to face interview of both male and female diabetes in rural and urban area of Wardha region. Result on basis of knowledge and awareness includes.55.36 \% $(P<0.05)$ urban and $43.44 \%$ rural people knew that diabetes is metabolic disorders.43.84\% $(P<0.05)$ urban and $27.55 \%$ rural people knew the symptoms of diabetes. $65.54 \%(P<0.05)$ urban, $39.21 \%$ rural people know that which factor affecting diabetes. $72.93 \%(P<0.05)$ urban, $37.60 \%$ rural population familiar about ranges about blood sugar levels. $53.91 \%(P<0.05)$ urban and $35.27 \%$ rural population aware that diabetes can cause complications in other organs. $72.37 \%(P<0.05)$ urban and $43.37 \%$ rural population aware that obesity can cause diabetes. $68.45 \%(P<0.05)$ urban $\& 57.43 \%$ rural population accepted that sedentary lifestyle as main cause of diabetes. $76.51 \%(P<0.05)$ urban and $42.12 \%$ rural population aware about impact of diet plan. $60.51 \%$ $(P<0.05)$ urban and $32.21 \%$ rural agreed that diabetes can be prevented if necessarily care should be taken. $88.14 \%$
$(P<0.05)$ urban and $62.82 \%$ rural population found cardiovascular is major complication. $68.56 \%$ urban and $72.30 \%$ $(P<0.05)$ rural population suffer from retinopathy.52.62\% urban and $40.04 \%$ rural suffer from nephropathy. $29.44 \%$ rural, $12.52 \%$ urban population suffers from foot ulcers. $48.76 \%$ urban and $32.21 \%$ rural population cause memory impairment in diabetes. $68.45 \%(P<0.05)$ urban and $29.30 \%$ rural population has family history was the main risk factor. $62.41 \%(P<0.05), 28.27 \%$ rural population show obesity. $49.21 \%(P<0.05)$ urban and $27.98 \%$ rural population found sedentary lifestyle to be cause of diabetes. This is evidence that patient education is the most effective way to lessen the complications. The finding of the present survey reveals that a high prevalence of diabetes was associated with poor awareness of diabetes in Wardha region.

Conflicts of interest None

\section{References}

1. Raheja BS, Kapur A, Bhoraskar A, Sathe SR, Jorgensen LN, et al. Diabetes Care Asia-India study: diabetes care in India-current status. J Assoc Physicians India. 2001;49:717-22.

2. Shah VN, Kamdar PK, Shah N. Assessing the knowledge attitudes and practice of type 2 diabetes among patients of saurashtra region, Gujarat. Int J Diabetes Dev C Tries. 2009;29:118-22.

3. Herman WH. Diabetes epidemiology: guiding clinical and public health practice. Diabetes Care. 2007;30:1912-9.

4. Geneva: World Health Organization; 2005. Preventing chronic diseases; A vital investment: WHO global report; p.2.

S. Kide $(\varangle) \cdot$ A. Rangari $\cdot$ R. Shiral $\cdot$ N. Mane $\cdot$ P. Yadav $\cdot$

$\mathrm{K}$. Ambulkar $\cdot$ C. Tenpe $\cdot$ A. Patole $\cdot$ M. Tundulwar $\cdot$ S. Rathod

Department of Pharmacology, Institute of Pharmaceutical Education

and Research Boragon (Meghe), Wardha 442001, MS, India

e-mail: kideshiv2010@gmail.com 